\title{
Discussion: Decision-support tools for sustainable
}

\section{drainage}

\section{Scholz}

\section{Virginia Stovin, University of Sheffield, UK}

I welcome this paper's contribution to research aimed at identifying issues and opportunities associated with sustainable drainage system (SUDS) retrofitting. I believe that there are significant potential benefits associated with the broader application of SUDS retrofitting in urban environments, which are presently underexploited. Readers may also be interested in other ongoing research in this area. Swan ${ }^{12}$ attempted to address this complex problem through the development of a set of decisionsupport flowcharts. ${ }^{13,14}$ The work of Singh et al. in Glasgow ${ }^{15}$ is also relevant, and CIRIA C609 includes a number of simple decision-making tools. Atkins ${ }^{16}$ presented an excellent review of SUDS retrofitting issues and opportunities, including some useful insights into practical implementation issues. SNIFFER has also recently undertaken relevant research (Project UE3(05)UW5), and many of the forthcoming DEFRA 'Making Space for Water' pilot projects will consider issues and opportunities surrounding SUDS retrofit. The European Daywater project ${ }^{17}$ aims to provide SUDS decision-support tools and approaches, while a recent UKWIR/WERF project report ${ }^{18}$ provides a comprehensive USA/UK review of SUDS performance and whole-life costs.

\section{Dr Scholz suggests that by utilising his approach, the} requirement for skill and judgement on the engineer's part may be eliminated. Though there is, without doubt, a need to develop generic guidance rules and tools that assist the engineer in carrying out the feasibility study and options appraisal process efficiently, I would argue that SUDS retrofitting is an area in which engineering judgement has a critical role to play. As with most other engineering design problems, individual site constraints will require the engineer to exercise judgement in developing and eliminating options. I invite the author to comment on the appropriate balance to be sought between decision-support tools and engineering judgement.

I have attempted to use the web-based tool he described with limited success. I would like to invite Dr Scholz to clarify whether this is intended for independent practitioner usage at this point in time.

\section{Author's reply}

I welcome Dr Stovin's reply to my paper because it highlights the different schools of thought and approaches to decision-support tools for sustainable drainage planning. Dr Stovin predominantly criticises the lack of background information summarising grey literature, which includes most of her own work on this subject matter. The proposed additional references provide some practical value to the practitioner. The reader is also encouraged to consult my new book ${ }^{19}$ and a recent relevant journal paper, ${ }^{20}$ for further, more detailed, information.

The original paper was initially accepted for publication in the Institution of Civil Engineers' (ICE) Civil Engineering journal before the ICE editorial office decided to publish in ICE Engineering Sustainability instead. The paper was therefore written for a broader audience that is perhaps less interested in drainage history. Moreover, a word limit was imposed on the paper, requiring the omission of background information including grey literature.

After reading the paper carefully, it should become apparent that the proposed approach allows either for direct engineering judgement input into the calculation process or its absence. Engineering judgement is obviously still required when using this decision-support tool, but its relative importance has decreased. This tool will therefore allow inexperienced engineers to design SUDS with greater confidence.

This is the first practical and scientific decision-support tool for SUDS planning that deals professionally with the complexity of the design problem by using the key site variables that are of greatest relevance to the practitioner. The proposed tool uses a transparent numerical approach that can easily be altered by the more confident planner to suit his or her specific needs.

This tool is not oversimplifying reality. Almost 200 real sites have been visited and assessed in detail. The diagrams 1-3 proposed by Dr Stovin and her student are also a useful tool for the practitioner during the initial stages of drainage planning. In fact, they are complimentary to this paper. The layout of the tables is simple and clear. It is beyond the scope of a scientific paper to discuss each practical detail potentially related to information provided in the tables-this would just bore the reader.

The web-based tool is based on free and simple student software that aims to generate feedback and discussion, and is not a 
commercial tool to be used by practitioners. The current version suggests solutions only if the input variables are appropriately chosen. In the meantime, the model has evolved considerably, but its content is not yet in the public domain.

My paper proposes a planning tool for sustainable drainage design-nothing more and nothing less. This is not a trivial task because it has great implications on issues such as cost, ownership and adoption. However, these topics were not within the scope of this paper.

\section{REFERENCES}

12. Swan A. D. A Decision-support System for the Design of Retrofit Sustainable Urban Drainage Systems (SUDS). PhD thesis, University of Sheffield, 2003. See http://www. retrofit-suds.group.shef.ac.uk/publications.html for further details.

13. Stovin V. R. and SwAN A. D. Application of a retrofit SUDS decision-support framework to a UK catchment. Proceedings of the 2nd National Conference on Sustainable Drainage, Coventry, 2003, 171-180.
14. Swan A. D. and Stovin V. R. A decision-support framework for the design of retrofit SUDS. Proceedings of the International Conference on Sewer Operation and Maintenance (SOM2002), Bradford, 2002.

15. Singh R., Stovin V., Jefferies C., Morrison G. and GILLoN S. Developing a planning and design framework for retrofit SUDS. Proceedings of the 10th International Conference on Urban Drainage, Copenhagen, 2005, CD-ROM.

16. AtKIns. SUDS Retrofit Research Report, 2004. See http:// www.scotland.gov.uk/Topics/Environment/Water/15561/ resreport for further details.

17. See http://daywater.enpc.fr/www.daywater.org/

18. LAMPE L. Post-project Monitoring of BMPs/SUDS to Determine Performance and Whole-life Costs: Phase 2. WERF, Alexandria, VA, 2005, Report 01-CTS-21T.

19. Scholz M. Wetland Systems to Control Urban Runoff. Elsevier, Amsterdam, 2006.

20. Zheng J., NanbaKhsh H. and Scholz M. Case study: design and operation of sustainable urban infiltration ponds treating storm runoff. Journal of Planning and Development, ASCE, 2006, 132, No. 1, 36-41. 